\title{
Plotino y Grosseteste: El neoplatonismo en la cosmología medieval ${ }^{*}$
}

\author{
Sebastián Ricardo Cristancho Sierra \\ Universidad del Rosario
}

\begin{abstract}
Resumen: En este trabajo se estudia el caso de la cosmología del filósofo y científico Robert Grosseteste como un ejemplo de la notable influencia del neoplatonismo en la ciencia medieval. Uno de los propósitos de la cosmología de Grosseteste consistió en explicar la secuencia efectiva de la creación del cosmos. Sostengo que la explicación que ofrece Grosseteste acerca de la creación es una expresión renovada de algunas ideas de Plotino a propósito de cómo el Uno engendra lo múltiple. Me interesa resaltar tres aspectos de la estrecha relación entre el sistema cosmológico de Grosseteste y el sistema metafisico de Plotino: (1) Unidad de principio, (2) Mecanismos de generación y (3) Unidad del sistema.
\end{abstract}

Palabras clave: Uno; luz; doble actividad; emanación; multiplicación

\begin{abstract}
Plotinus and Grosseteste: Neoplatonism in Medieval Cosmology". This work explores the case of cosmology of the philosopher and scientist Robert Grosseteste as an example of the remarkable influence of Neoplatonism in medieval science. One of the purposes of Grosseteste's cosmology was to explain the effective sequence of the creation of cosmos. I contend that the explanation provided by Grosseteste about creation is a renewed expression of some ideas of Plotinus with regard to how the One begets the multiple. I want to highlight three aspects of the relationship between the cosmological system of Grosseteste and the metaphysical system of Plotinus: (1) Unit of principle, (2) Mechanisms of generation and (3) Unit of system.
\end{abstract}

Key words: One; light; double activity; emanation; multiplication

\footnotetext{
Este trabajo fue fruto del proyecto de investigación 'La pirámide visual: evolución de un instrumento conceptual' patrocinado por el FIUR (Fondo de Investigaciones de la Universidad del Rosario). Agradezco a los estudiantes Susana Restrepo, Laura Álvarez, Daniel Pinzón, Nicolás Montenegro, de la Escuela de Ciencias Humanas de la Universidad del Rosario, y a los profesores Jorge Iván Salazar, de la Universidad del Rosario, y Carlos Augusto Hernández, del Departamento de Física de la Universidad Nacional de Colombia, por sus valiosos comentarios, siempre agudos y acertados. Sin embargo, debo especial gratitud al profesor Carlos Alberto Cardona Suárez, del programa de filosofia de la Universidad del Rosario, quien además de darme la oportunidad de participar en el proyecto, ha sido un ejemplo de dedicación y compromiso en la academia y de empeño y pasión por el conocimiento.
} 


\section{Introducción}

Durante la mayor parte de la Modernidad y la Ilustración, la ciencia medieval fue objeto de acérrimas críticas entre los círculos académicos. Los espíritus ilustrados, asombrados por el poder predictivo y los alcances de la ciencia moderna, y con frecuencia sin hacer el esfuerzo de volver a los trabajos de sus predecesores, vieron en los científicos medievales expresiones de una época oscura para el pensamiento. Esta opinión, robustecida con el correr de los años, derivó en un arraigado rechazo hacia la ciencia medieval y hacia la obra de sus máximos representantes. Por fortuna, desde finales del siglo XIX surgió un renovado interés por el estudio de la ciencia desarrollada durante la Edad Media, y un gran número de filósofos y científicos medievales, otrora vilipendiados, han sido progresiva y justamente redimidos. Entre ellos destaca la figura de Roberto Grosseteste ${ }^{1}$ (1170c-1253). Los datos biográficos que se tienen de él son en su mayoría aproximaciones, sobre todo aquellos de sus primeras seis décadas de vida. De lo que no hay duda es del impacto que tuvo entre sus contemporáneos y sus más inmediatos seguidores, especialmente entre los franciscanos. Se sabe que Grosseteste nació en Stowe, un poblado cerca de Londres, y que recibió educación en Londres y posiblemente también en París. En el año 1214 llegó a ser canciller de la recién fundada Universidad de Oxford, y desde 1235 se convirtió en obispo de Lincoln, cargo que ocupó hasta su muerte en $1253^{2}$.

Grosseteste realizó distintos aportes a la ciencia y a la filosofia medieval, aportes que se pueden clasificar en cuatro grupos: (1) Aportes a la ciencia natural: en el mundo occidental, el obispo de Lincoln fue uno de los primeros científicos en insinuar algo parecido a un método experimental para someter a escrutinio las hipótesis teóricas. También fue uno de los primeros en advertir la necesidad de otorgar un papel relevante a las matemáticas en la comprensión de los fenómenos naturales³; (2) Aportes a la óptica: en estrecha relación con sus

\footnotetext{
1 También son comunes las variaciones: Robert Grosseteste o Roberto Grossatesta.

2 Un estudio biográfico muy cuidadoso puede encontrarse en McEvoy, J., Robert Grosseteste, Oxford: Oxford University Press, 2000.

3 Los tratados en los que Grosseteste argumenta a favor de la matemática como poderoso instrumento para comprender los fenómenos naturales y de la "experimentación" como herramienta para validar hipótesis teóricas son: De lineis, angulis, et figuris, De íride y De natura locorum.
} 
aportes a la ciencia natural, Grosseteste desarrolló una teoría geometrizante de la luz y de la percepción, teoría que en el transcurso de unos pocos años sería el detonante principal de la óptica naciente en el seno de Oxford. Actualmente Grosseteste es conocido especialmente por enunciar el que para muchos es el primer intento de ofrecer una ley cuantitativa de la refracción ${ }^{4}$; (3) Aportes relacionados con la asimilación del pensamiento clásico: sin ser ortodoxo, el obispo se nutrió de muchas vertientes del pensamiento aristotélico y neoplatónico, y en la mayoría de sus obras intentó recuperar parte del espíritu clásico para ponerlo al servicio de nuevos problemas. Grosseteste dominaba el griego, y entre los trabajos de su autoría se cuentan traducciones y comentarios a la obra de Aristóteles (especialmente la Física y la Metafisica); (4) el cuarto grupo de los aportes y desarrollos de Grosseteste a la ciencia y la filosofia medieval, grupo al cual está dedicado el presente texto y sobre los cuales no se dirá ahora mayor cosa, lo conforman los aportes en el terreno de la metafísica y la cosmología. El obispo elaboró un sistema cosmológico con el que intentó la no sencilla tarea de conciliar el pensamiento clásico con las ideas cristianas, y en los tratados en los que se dedicó a esta empresa ofreció los cimientos metafísicos de gran parte de su obra.

El propósito de este texto es explorar las relaciones y correspondencias de la cosmología de Grosseteste con el sistema metafísico de Plotino. Se sostiene que la preocupación fundamental de la cosmología del obispo, a saber, explicar el proceso de creación del cosmos, es una expresión renovada del problema que siglos antes Plotino planteó y resolvió a propósito de cómo el Uno engendra lo múltiple. Para tal efecto se seguirán cinco pasos: primero, se presentarán algunos aspectos generales relacionados con el sistema metafísico de Plotino,

\footnotetext{
La traducción al inglés de los dos primeros tratados fue hecha por D. Lindberg y está recogida en Grant, E., A Source Book in Medieval Science, Cambridge (Mass): Harvard University Press, 1974. Una presentación bilingüe latín-español de las principales obras de Grosseteste fue llevada a cabo por Celina Lértora Mendoza en cuatro volúmenes: Astronomía, Física, Óptica y Metafisica, tres de ellos referidos en la bibliografia. Un estudio detallado sobre Grosseteste y el método experimental pueden encontrarse en Crombie, A.C, Robert Grosseteste and the Origins of Experimental Science, Oxford: The Clarendon Press, 1953., y sobre Grosseteste y el papel de las matemáticas en la ciencia natural en Lindberg (1982).

4 Sobre los aportes de Grosseteste en el campo de la óptica medieval pueden consultarse Eastwood, B, "Medieval Empiricism: the Case of Grosseteste's Optics", en: Speculum: A Journal of Mediaeval Studies, v. XLII, 2 (1968), pp. 306-321, y sobre Grosseteste y la ley cuantitativa de la refracción Eastwood, B., "Grosseteste's "Quantitative" Law of Refraction: A Chapter in the History of Non-Experimental Science", en: Journal for the History of Ideas, v. XXIIX, 3(1967), pp. 403-414; "Metaphysical Derivation of a Law of Refraction: Damianos and Grosseteste", en: Archive for History of Exact Sciences, v. VI, 3 (1970), pp. 224-236 y Turbayne, C., "Grosseteste and the Ancient Optical Principle", en: Isis, v. L, 4 (1959), pp. 467-472.
} 
haciendo especial énfasis en las propiedades que se conceden al Uno y en las tensiones que dan lugar al problema acerca de la generación de la multiplicidad a partir de una unidad anterior; segundo, se explicará la solución que ofrece Plotino a esas tensiones (la respuesta la encontramos en la teoria de la doble actividad); tercero, se expondrán las principales vías que posibilitaron la llegada y asimilación del pensamiento clásico en el contexto medieval europeo; cuarto, se dará una semblanza general de la cosmología de Grosseteste, tal como aparece en el tratado De luce; y quinto, se mostrarán detalladamente las relaciones entre la narración cosmológica de Grosseteste y la metafísica de Plotino.

\section{Plotino: la existencia y los predicados del Uno}

Plotino (203c-270) es considerado el fundador y máximo representante del neoplatonismo. Su obra fue editada por Porfirio, su discípulo y amigo, en lo que ahora se conoce como las Enéadas ${ }^{5}$ : seis libros, cada uno compuesto de nueve tratados -de ahí el nombre- en donde se despliega un amplio y rico sistema de filosofia.

Para Plotino, la realidad es un eterno despliegue dinámico, un proceso continuo e ininterrumpido en el que los seres, por un poder inherente a su naturaleza, producen incesantemente otros seres de fuerza y naturaleza inferior. Ese despliegue se extiende indefinidamente. Las potencias generadoras engendran productos que, a su vez, cuando alcanzan su grado de perfección, engendran nuevos seres. El proceso se caracteriza por un debilitamiento progresivo de las cosas generadas. En cada paso de la cadena de generación, lo engendrado resulta menor en fuerza y vida comparado con sus antecesores. Esto conduce a una concepción jerárquica de la realidad, una realidad estructurada en distintos niveles o grados ontológicos que oscilan desde lo más perfecto, lo inaprehensible, lo absoluto, la positividad en grado sumo, hasta lo carente de toda forma y vida, hasta la absoluta negación. En el primer nivel, el nivel supra ontológico, más allá del ser, como el origen de toda cadena productora, se encuentra el Uno (tò hén), principio inefable y fuente creadora de todas las cosas.

El Uno no aparece a los sentidos; ante ellos solo se presenta una multiplicidad abundante y copiosa de seres, extraordinariamente rica, compleja

\footnotetext{
5 Las referencias a las Enéadas de Plotino se harán mencionando en primer lugar la Enéada (números romanos) seguido del tratado, el capítulo y la(s) líneas(s) citada(s) (números arábigos), según la numeración original. Se seguirá la edición de las Enéadas traducida y comentada por Jesús Igal: Plotino, Enéadas, Igal, J. (trad.), Madrid: Gredos, 1992.
} 
y heterogénea. ¿Cómo se tiene, pues, noticia de esa unidad anterior a la multiplicidad? La existencia del Uno es una exigencia de la razón ${ }^{6}$. Plotino tiene como cierto e indiscutible que no puede haber pluralidad o multiplicidad sin una unidad que la preceda y la fundamente. La pluralidad requiere de una unidad anterior pues sin ella quedaría "despedazada en miembros dispersos, que concurrirán a la composición acudiendo al azar, uno de una parte y otro de otra" (V, 3, 12, 13-15). Sin unidad todo sería desorden y caos. Pero esto no sucede; al contrario, los seres están armoniosamente configurados a pesar de su naturaleza múltiple y heterogénea, y sus componentes o atributos ${ }^{7}$, siendo de la más variada naturaleza, están articulados de manera ordenada. Y esto solamente puede suceder gracias a la presencia de un principio unificador, un principio sin el cual los seres se desintegrarian en partes y perderian su esencia. La multiplicidad encuentra entonces en la Unidad el fundamento de su ser. En palabras de Plotino: "todo lo que no es uno, por la unidad se salva y por la unidad es lo que es" (V, 3, 15, 10-15), "todos los seres por la unidad son seres" (VI, 9, 1, 1-5). Las pruebas que presenta el filósofo en favor de la existencia necesaria del Uno parten de los posteriores a él y, advirtiendo su multiplicidad, concluyen la existencia de esa unidad anterior que soporta el ser de todas las cosas ${ }^{8}$.

Además de la necesidad de su existencia, Plotino señala que al Uno lo pensamos a través de ciertos predicados ${ }^{9}$. Presentamos a continuación una lista con algunos de ellos.

\footnotetext{
6 La existencia del Uno es una exigencia de la razón. Sin embargo, de acuerdo a Plotino, cuando decimos que el Uno debe existir no debemos pensar que él está condicionado a alguna modalidad de ser y que la existencia es un atributo que lo determina. Simplemente decimos que la razón nos impone la necesidad de su existencia, pero nada afirmamos acerca de su naturaleza. Para Plotino, el Uno escapa a cualquier aprehensión racional. Esto nos conduce a una situación paradójica. Por un lado, la existencia del Uno aparece como una demanda racional; por otro lado, el Uno escapa a cualquiera de nuestros razonamientos. La utilidad de los razonamientos acerca del Uno, como aquellos que nos indican la necesidad de su existencia, es fundamentalmente una utilidad persuasiva. Véase nota 9.

Esos componentes son muy variados. Pueden referirse a las partes que conforman un ser o a los predicados y modalidades que a él convienen. Así, por ejemplo, un hombre es múltiple porque su cuerpo consta de partes, pero también por el simple hecho de "tener cuerpo", y además es múltiple en la medida que es "animal" y es "racional". Es más, los seres son múltiples simplemente en la medida en que "son seres".

8 No se explorarán en sus detalles las "demostraciones" que Plotino sigue de la existencia del Uno, pues ello requeriria introducir y desarrollar muchos aspectos de la metafisica plotiniana que extenderían demasiado este texto y poco ayudarian para lo que se pretende defender. El lector interesado puede consultar, por ejemplo, el tratado 9 de la Enéada VI o los tratados 1, 2 y 3 de la Enéada V. Plotino también ofrece demostraciones de la existencia del Uno a partir de analogias con los números. Véase, por ejemplo, V, 5, 4-5.

9 Llamamos la atención sobre la expresión lo pensamos. Esto por una tensión que el propio Plotino plantea repetidas veces relacionada con las restricciones que debemos tener cuando
} 
(1) El Uno es principio (originativo) de todas las cosas (V, 4, 11, 15-20). El Uno precede a todas las cosas. Se ubica en el más alto grado de la cadena productora. Es principio originativo en la medida que no está particularizado en los seres a los que da origen -como es el caso de los principios constitutivos-, sino que se trata de un principio anterior y distinto de las cosas posteriores a él, un principio que genera sin estar él mismo presente en lo generado ${ }^{10}$.

(2) El Uno es único ( $\mathrm{V}, 4,1,15-20)$. Si hubiese dos o más como él, habría entonces multiplicidad y, por tanto, ellos no serían Uno.

(3) El Uno es causa de todas las cosas (III, 8, 10, 1). El Uno es la causa creadora de todos los seres. No una causa intermitente, sino una causa activa e ininterrumpida, que genera incesantemente. Una potencia que siempre se está realizando en acto y que no depende de nada más que ella misma.

(4) El Uno es lo más perfecto. "[L]a causa es superior a lo causado" (V, 5, 13, 39), escribe Plotino. Siendo el Uno la causa de todas las demás cosas, debe, por tanto, ser superior a todo cuanto existe, debe ser lo más perfecto ${ }^{11}$.

(5) El Uno es simple. Plotino concedía, junto con los filósofos antiguos, que en "todos los casos el que engendra es más simple que lo engendrado" (III, 8, 9, 43). De manera que el Uno, al ser la potencia de la cual todo ser toma existencia, ha de ser también lo más simple. La simplicidad

hablamos acerca del Uno. Cuando atribuimos al Uno determinados predicados, sostiene Plotino, no debemos suponer que el Uno es el sujeto de tales predicados, puesto que "nada se predica de él" (V, 3, 13, 5), "no el ser, no la esencia, no la vida, [pues el Uno] es lo que sobrepasa todas estas cosas" (III, 8, 10, 31-32). Sin embargo, "nosotros tratamos de designárnoslo a nosotros mismos como podemos" (V, 3, 13, 5-7). En la filosofia de Plotino, la utilidad principal que se obtiene de discurrir y razonar acerca del Uno es la persuasión: "hablamos y escribimos acerca de él como señalando el camino a quien desee un punto de contemplación, tratando de remitirle a aquel y de despertarle de los razonamientos a la contemplación" (VI, 9, 4, 10-15). Siguiendo a Santa Cruz y Crespo (Santa Cruz, I. y M. Crespo, Plotino: de la filosofía a la mística. Enéadas: Textos esenciales, Buenos Aires: Ediciones Colihue, 2007, pp. XXXI-XXXII), podemos hablar del Uno de cuatro maneras: (1) negativamente, enunciado lo que el Uno no es; (2) regresivamente, hablando del Uno a partir de aquello generado por él; (3) metafóricamente; y (4) usando cláusulas restrictiva como "por así decirlo" en los enunciados que hagamos de él.

${ }^{10}$ Un ejemplo de principio originativo es la fuente de los ríos. Cada río tiene un origen en alguna fuente natural de la cual toma su vida; sin embargo, ese origen no está presente a lo largo de los cauces. La fuente permanece en un lugar determinado desde donde nutre al río de todas sus aguas.

11 Ello no quiere decir que las demás cosas, cuyo ser depende del Uno, no puedan alcanzar la perfección. El sistema metafísico de Plotino acepta grados de perfección, de manera que cualquier ente puede llegar a ser perfecto en la medida que su naturaleza se lo permita. 
del Uno está estrechamente relacionada con su indivisibilidad: por su absoluta simplicidad, el Uno no se puede dividir ni descomponer en modo alguno.

Estas propiedades del Uno no parecen problemáticas. No hay tensiones entre ellas, no se contradicen, ninguna afirma algo que otra niega; al contrario, están estrechamente relacionadas y unas pueden verse como consecuencia de otras. Sin embargo, ocurre algo diferente con los dos siguientes atributos que Plotino insistentemente considera propios del Uno:

(6) El Uno engendra de manera ininterrumpida.

(7) El Uno permanece en sí mismo.

El Uno debe engendrar de manera ininterrumpida pues vemos "que las otras cosas que alcanzan su perfección [las potencias distintas del Uno], engendran y no se contentan con permanecer en sí mismas sino que producen otra cosa" (V, 4, 1, 27-29). De manera que el Uno, siendo la potencia primera, la más potente y perfecta de todas, y de la que dependen todos los demás seres, no debe quedarse en sí mismo, sino que, con mucha más razón, debe engendrar, y debe hacerlo de manera ininterrumpida ${ }^{12}$. Pero el Uno también debe permanecer en sí mismo, toda vez que el movimiento es señal de necesidad, de imperfección. Los seres se ponen en movimiento porque de algo carecen. Solo entonces emprenden actividad, tratando de conseguir ese algo que no poseen: "[T]odo lo que se mueve debe tener alguna meta hacia la que se mueva" (V, 1, $6,16)$. El Uno, sin embargo, es perfecto, no necesita ni desea nada y no tiene meta alguna, de manera que, en gracia de su perfección absoluta y completa autosuficiencia, debe permanecer en sí mismo.

Aparece ahora un conflicto de la razón: ¿cómo puede el Uno engendrar si permanece en sí mismo? Si el Uno engendra ininterrumpidamente, no se quedaría en sí mismo, toda vez que engendrar es una acción; en tanto que si el Uno se queda siempre en sí mismo, no realizaría acción alguna y no engendraría. Pero si negamos que el Uno engendra ininterrumpidamente también negariamos su papel como primera y más potente de las potencias, y si negamos que permanece en sí mismo negariamos su perfección. El Uno cuenta entonces

\footnotetext{
${ }^{12}$ Este razonamiento es uno de los varios ejemplos en los que Plotino habla del Uno a partir de los posteriores a él. Para persuadirnos de que el Uno siempre genera, Plotino alude a las potencias de la naturaleza (los animales, las plantas, el fuego, el hielo, etcétera) y a las regularidades de sus procesos de generación. Esas potencias no se quedan en sí mismas sino que, cuando completan su desarrollo, generan algo distinto de ellas. Los animales y las plantas engendran su descendencia, el fuego produce calor, el hielo, frío.
} 
con dos propiedades que reconocemos como necesarias en él y que son a primera vista contrarias entre ellas. ¿Cómo conciliarlas?

Esta situación se presenta también con otro par de predicados atribuidos al Uno. Para verlo, citemos en extenso a Plotino: "Porque el Uno está en todas partes; no hay donde no esté. Llena, por tanto, todas las cosas. Luego existen muchas, o mejor, ya existen todas. Porque si el Uno se limitara a estar en todas partes, él mismo sería todas las cosas. Pero como además no está en ninguna parte, todas las cosas se originan, sí, por él, pues aquel está en todas partes, pero son distintas de él porque él mismo no está en ninguna parte" (III, 9, 4, 2, cursivas mías). De un lado, dice Plotino, el Uno está en todas las cosas, en tanto que, de otro lado, es distinto de ellas, está más allá de ellas y no está particularizado en ellas. Así pues, tenemos:

(8) El Uno es omnipresente.

(9) El Uno es trascendente.

¿Cómo puede el Uno ser omnipresente a la vez que trascendente? ¿Cómo puede estar en todas la cosas y estar más allá de ellas?

\section{Plotino: solución al problema de la generación de lo múltiple a partir del Uno}

El problema metafísico que surge al aceptar que el Uno engendra a la vez que permanece en sí mismo aparece de manera reiterada en la obra de Plotino. En la quinta Enéada encontramos una de las expresiones más claras de la dificultad: “¿Cómo de un uno que es tal cual decimos que es 'el uno' tomó existencia cosa alguna, ya sea una multiplicidad, o una Diada o un Número? ¿Y cómo, por el contrario, aquel no se quedó en sí mismo sino que emanó de él esa multiplicidad tan copiosa que aparece a la vista de los seres, pero que estimamos que hay que reducirla a aquel?" (V, 1, 6, 3-8). Para resolver el conflicto, Plotino recurre a la teoría de las dos actividades. Todos los seres, asegura, poseen dos actividades (energeia) inherentes a su naturaleza: "Es que una es la actividad de la esencia y la otra la actividad derivada de la esencia de cada cosa. La actividad de la esencia de cada cosa es la cosa misma en acto, la actividad derivada de la esencia es la que forzosamente debe subseguir a cada cosa, siendo distinta de ella" (V, 4, 2, 25-30). Algunos ejemplos y analogías que sugiere el filósofo para explicar su teoría son el calor del fuego y la luz de los cuerpos luminosos. Según Plotino, el calor del fuego es doble. Posee un calor propio, inseparable de su ser, un calor esencial, y de él emana otro calor que lo rodea y se expande hacia el exterior -como aureándolo, diría Plotino- sin mengua del calor interior, 
que permanece imperturbable en el cuerpo. El calor exterior lo podemos sentir en las cercanias del fuego sin necesidad de tocar directamente la llama. Así las cosas, uno es el calor en el fuego y otro el calor en el medio. Del mismo modo ocurre con la luz de los cuerpos luminosos: una luz pertenece al cuerpo luminoso como una propiedad intrinseca e inseparable de él, en tanto que la otra emana de la primera luz liberándose en el medio que rodea al cuerpo. Una es luz en el cuerpo y la otra luz en el medio ${ }^{13}$.

Más allá de ser algo accidental, propio de algunos seres sensibles, la doble actividad es, para Plotino, un principio general de la realidad, un principio que se manifiesta en todos los seres: "Y todos los seres, mientras permanecen, emiten necesariamente de su propia substancia una entidad que está suspendida, en torno a ellos y por fuera de ellos, de la potencia presente en ellos, siendo una imagen de los que son algo así como sus modelos, de los cuales provino..." (V, $1,6,30-35)^{14}$. Los seres poseen entonces una actividad que subsiste en ellos como algo propio de su esencia, actividad que permanece mientras la cosa que la produzca exista. Plotino la llama actividad interna. Pero además de esta hay otra actividad que no permanece en las cosas sino que las desborda y es emitida a la manera de copias o imágenes de la primera, rodeando a la cosa que la produce. Plotino la llama actividad externa. La relación entre la primera y la segunda actividad, entre lo interno y lo externo, es dual. En un sentido son diferentes, toda vez que la actividad segunda no es la primera; se trata de otra actividad (el calor y la luz en el medio son distintos del calor y la luz en los cuerpos, son otra luz y otro calor). En otro sentido son semejantes, toda vez que la segunda actividad preserva los rasgos de la primera, como copias o imágenes

\footnotetext{
${ }^{13}$ El ejemplo de la luz merece especial atención en relación con la influencia neoplatónica en los filósofos y científicos de la Edad Media. Los estudiosos medievales tendrán una particular fascinación por la distinción luz en el cuerpo (lux) - luz en el medio (lumen) para explicar fenómenos asociados a la percepción visual y, de manera más general, la tomarán como el ejemplo paradigmático para dar cuenta de los mecanismos de replicación causal en el mundo. Grosseteste será uno de los filósofos y científicos que encabezará esta empresa, a la que también pertenecieron Dante, Alberto Magno, Bartolomé el inglés y Roger Bacon, entre otros. Sobre la influencia de Plotino en la distinción medieval Lux-Lumen, $c f$. Raizman-Kedar, Y., "Plotinus's Conception of Unity and Multiplicity as the Root to the Medieval Distinction Between Lux and Lumen", en: Studies in History and Philosophy of Science, 37 (2006), pp. 379-397.

${ }^{14}$ Este pasaje es especialmente relevante en la medida que anticipa la idea fundamental del término especie, muy desarrollado en la filosofia medieval. En general, los filósofos medievales entendian por especies de un objeto las imágenes o simulacros que este creaba a su alrededor. Sostenian, por ejemplo, que las especies de un color emulaban el color real de las cosas que las producían. En los comienzos de la modernidad filosófica, el término especie también fue utilizado en relación con el término idea.
} 
de esta (el calor y la luz en el medio, si bien son otro calor y otra luz, semejan las características del calor en el fuego y de la luz en los cuerpos luminosos).

Por analogía con los seres, la doble actividad también puede pensarse en el Uno. Hay una actividad inherente a él, una actividad interna, y ella es la que asegura la permanencia del Uno en sí mismo, de la misma manera que el calor interno del fuego permanece siempre en el fuego. Pero además hay otra actividad del Uno, una actividad derivada o resultante de la primera, en virtud de la cual el Uno genera copias o imágenes suyas, dando origen a algo distinto de él, fuera de él, así como el calor interno del fuego es fuente de otro calor que se expande en el medio. En la teoría de la doble actividad encontramos, pues, la respuesta a la pregunta relativa a cómo el Uno engendra las demás cosas a la vez que permanece en sí mismo. La primera actividad, la actividad interna, asegura su permanencia, en tanto que la segunda garantiza su capacidad generativa. A la pregunta “¿Cómo es que brota de él la multiplicidad?” $(\mathrm{V}, 3,15,5-10)$, Plotino responde: "cabe responder que como el halo de luz de la luz" (V, 3, 15, 5-10); el Uno genera a la manera de "una radiación circular emanada de él... pero emanada de él mientras él permanece, al modo del halo del sol que brilla en su derredor como aureándolo, brotando perennemente de él mientras él permanece" (V, 1, 6, 30-35).

Con la teoria de la doble actividad también se solucionan la aparente contradicción entre la trascendencia y la omnipresencia del Uno. El Uno permanece en sí mismo, y al hacerlo se ubica más allá de todas las cosas, sin mezclarse con ellas o estar particularizado en ellas. En este sentido es trascendente. Pero en tanto que emana de sí mismo copias o imágenes suyas, imágenes que guardan semejanza con él, todos los seres, cualquiera sea su lugar o nivel en el proceso de generación, participan de la unidad primordial de la que reciben directa o indirectamente su existencia y gracias a la cual subsisten. En cada ser, por tanto, está presente el Uno de manera debilitada y tenue. En este sentido es omnipresente.

La generación ininterrumpida que tiene lugar a partir del Uno es un proceso que podemos entender bajo la forma de emanaciones o como una suerte de procesión ${ }^{15}$. Del Uno emanan los demás seres como imágenes que

\footnotetext{
${ }^{15}$ Hablar de emanación y de procesión no es equivalente. Jesús Igal (Introducción general. Vida de Plotino, en Plotino, Enéadas I-II, Igal, J. (trad.), Madrid: Gredos, 1992) favorece una posición según la cual las emanaciones plotinianas deben entenderse más bien como una procesión: "La procesión plotiniana se parece, pues, a la emanación, pero no es emanación; no hay emisión de partículas con pérdida de propia substancia, ni retransmisión de energía con desgaste de la propia" (p. 34). Para los fines de este texto no es importante la distinción.
} 
imitan la naturaleza de su progenitor. La generación ocurre en tres momentos ${ }^{16}$ : primero, la procesión, el despliegue dinámico que tiene lugar a partir del Uno; segundo, la conversión contemplativa ${ }^{17}$; y tercero, la autoconstitución o autodeterminación. El primer momento está asegurado por la segunda de las dos actividades. El Uno se desborda y genera, y lo hace sin mengua de su propio ser. Sin embargo, el producto inmediato de ese desborde no es un ser completamente constituido, sino un producto relativamente indeterminado e informe ${ }^{18}$. Por ello son necesarios el segundo y el tercer momento. El ser generado se detiene y se vuelve hacia su progenitor, lo contempla, y, queriendo imitarlo, se autoconstituye y autodetermina. De esta manera tiene lugar la Inteligencia. A partir de ella, de modo similar, tiene su origen el Alma. El Alma, por su parte, se subdivide en alma superior y alma inferior. El alma inferior corresponde a la naturaleza o mundo sensible. Uno, Inteligencia y Alma son las tres hipóstasis que conforman la realidad en el sistema plotiniano.

En los tres momentos del proceso de generación se manifiestan dos principios fundamentales. El primero de ellos es el principio de la productividad de lo perfecto. De acuerdo a este principio "todos los seres... cuando son ya perfectos, procrean" (V, 1, 6, 30-35). El segundo principio es el principio de la degeneración progresiva, de acuerdo con el cual los seres generados son siempre de naturaleza inferior a la de su progenitor. Toda copia o imagen emanada de las cosas es más débil que la cosa misma en acto. Cuando los seres generados se autoconstituyen y autodeterminan, alcanzan la perfección que su naturaleza les permite-menor a la de su progenitor- $y$, una vez en ese estado, se convierten ellos mismos en potencias productoras.

\section{Plotino-Grosseteste: la asimilación medieval del espíritu clásico}

Por el momento dejaremos de lado la metafísica de Plotino y mencionaremos brevemente las razones históricas que posibilitaron la llegada, transmisión y asimilación de las ideas de Plotino y, en general de grandes porciones del saber clásico, al ambiente intelectual inglés de finales del siglo XI y principios

${ }^{16}$ Cf. Santa Cruz, I. y M. Crespo, Plotino: de la filosofia a la mística, o.c., p. XLIII.

${ }^{17}$ La contemplación para Plotino no es sinónimo de pasividad. Al contrario, contemplación es acción y producción. Al contemplar a su antecesor, los seres recuperan lo más íntimo y perfecto de ellos mismos y se acoplan con su creador. Al hacerlo, se perfeccionan y engendran.

${ }^{18}$ No se trata de un producto completamente indeterminado e informe. Para Plotino estos son rasgos propios de la materia bruta. Se trata en cambio de una indeterminación relativa con respecto a la determinación que el producto inmediato está en condiciones de recibir (Santa Cruz, I. y M. Crespo, Plotino: de la filosofia a la mística, o.c., p. XLIII). 
del XII, contexto en el que se formó Grosseteste. Quisiera resaltar dos vías importantes que favorecieron el contacto. La primera está relacionada con las traducciones del árabe al latín de algunas de las principales obras de los sabios griegos y árabes; la segunda, con la receptividad de ambiente intelectual inglés.

$\mathrm{El}$ mundo árabe contaba con extensas bibliotecas en las que se encontraban trabajos de los principales autores griegos. En algunos lugares se fundaron institutos de investigación dedicados a recuperar el saber clásico. El más importante de ellos fue La Casa de la Sabiduria, fundado en Bagdad en el siglo IX bajo el mecenazgo de los califas Abasies. Pero la importancia del mundo árabe no se agotó en el acopio y la traducción de textos. Círculos de intelectuales dieron un paso adelante y elaboraron detallados comentarios a las obras de los filósofos clásicos, adoptando originales lecturas y exhibiendo nuevas interpretaciones. Entre los intelectuales más representativos del mundo islámico encontramos a Hunayn ibn Ishaq (808-873), Al-Kindi (801-873), Alhacén (965-1040), Al-Farabi (c. 870-950), Avicena (c. 980-1037), Avicebrón (c. 1020-1058) y Averroes (1126-1198).

Por otro lado, el Occidente latino nunca estuvo completamente aislado del oriente islámico y de sus logros intelectuales, pero el conocimiento de tales logros fue bastante limitado ${ }^{19}$. A partir del siglo XI, sin embargo, las condiciones sociales y económicas favorecieron un interés por los trabajos árabes y griegos. Las situaciones que promovieron ese interés fueron muchas y muy complejas. Entre ellas destaca el crecimiento de las escuelas urbanas en el siglo XI, que con intereses mucho más amplios desplazaron la educación monacal y despertaron una creciente fascinación por la tradición filosófica, fascinación que dio lugar, en el siglo XII, al auge de la traducción de textos clásicos del árabe y el griego al latín ${ }^{20}$. También fue importante la aparición, a finales del siglo XII y principios del XIII, de las universidades (especialmente las de Bolonia, Oxford y París), lugares donde el nuevo saber fue acogido con beneplácito. Entre los siglos XI y XIII aparecieron traducciones de Aristóteles, Platón, Euclides, Ptolomeo,

\footnotetext{
${ }^{19}$ Exceptuando algunas pocas traducciones del griego al latín llevadas a cabo por Boecio y Caldicio (Caldicio fue el autor de la versión más popular del Timeo de Platón durante la Edad Media), el conocimiento que se tenía en Occidente de los autores griegos y árabes estaba limitado a textos de divulgación que presentaban de manera sencilla y resumida los logros de la ciencia griega. Este es el caso, por ejemplo, de Las nupcias de Filología y Mercurio de Marciano Capella (s. V d.C.).

${ }^{20}$ Los traductores más destacados de la época fueron Gerardo de Cremona, quien tradujo numerosos textos del árabe al latín, y Jacopo de Venecia, quien hizo lo propio a partir de textos escritos originalmente en griego.
} 
Al-Kindi, Alhacén y Galeno, entre otros, que poblaron paulatinamente las bibliotecas de los principales centros académicos de Europa.

La aparición de las traducciones latinas de las principales obras de los filósofos clásicos no fue suficiente para la asimilación de su pensamiento. Los textos circularon, pero en la medida que se conocieron muchos de ellos fueron censurados. Gran parte de la obra de Aristóteles corrió con esta suerte ${ }^{21}$. Sin embargo, el ambiente intelectual inglés fue particularmente receptivo (o al menos no tan restrictivo) ante las nuevas ideas ${ }^{22}$. Se leía a Aristóteles sin tanta prevención como en otras partes de Europa y, en lugar de condenarlo por sostener tesis contra la libertad o el creacionismo, personajes como Grosseteste procuraron articular grandes porciones del pensamiento aristotélico en un sistema compartido con el cristianismo y el neoplatonismo.

Aunque no hay completa certeza sobre la manera en que Grosseteste se acercó inicialmente al pensamiento neoplatónico y a las ideas de Plotino, son varios los caminos plausibles que pudieron favorecer el contacto. Entre las obras traducidas al latín se encontraban textos de Avicena (c. 980-1037). Gracias a ellos, los filósofos medievales pudieron conocer gran parte de las orientaciones neoplatónicas. Avicena tenía a su disposición una traducción al árabe de algunos pasajes de las Enéadas IV, V y VI, que habia sido preparada en Bagdad por el círculo de Al-Kindi a partir de una versión anterior traducida al árabe directamente desde el griego ${ }^{23}$. El impacto de Avicena en el pensamiento occidental de la Edad Media fue enorme, y quizá este fue el vehículo principal de transmisión, pero también fueron muy influyentes obras de otros autores neoplatónicos como Al-Kindi (801-873) o Dionisio Areopagita (aprox. 500 d. C.).

\footnotetext{
${ }^{21}$ La prohibición de la obra de Aristóteles estuvo asociada al hecho de que el pensamiento aristotélico no se ajustaba a algunos preceptos básicos del cristianismo. Aristóteles, por ejemplo, defendía la eternidad del cosmos y favorecía el determinismo, ideas que se oponían fuertemente a las tesis creacionistas y a la idea cristiana del libre albedrío.

${ }^{22}$ Ello no quiere decir que en el contexto inglés se aceptara con sumisión la doctrina aristotélica o se estuviera de acuerdo con todo lo que ésta enseñaba. Así como en París hubo dos grandes condenas contra la obra de Aristóteles (las condenas emitidas por el obispo Étienne Tempier en 1270 y 1277) en Inglaterra también se decretaron prohibiciones (también en 1277, renovada en 1284 por John Pecham), pero estas nunca fueron tan estrictas como en Francia y otras partes de Europa (Lindberg, D., Los inicios de la ciencia occidental, Beltrán, A. (trad.), Barcelona: Paidós, 2002, pp. 297-305).

${ }^{23}$ Esta traducción circuló bajo el nombre de La teología de Aristóteles.
} 


\section{Grosseteste: el origen del cosmos}

Cualesquiera hayan sido las vías de transmisión, el saber clásico tuvo un impacto incontestable en los desarrollos de la ciencia y la filosofia medieval. La cosmología no fue la excepción. Uno de los propósitos principales de la cosmología medieval consistió en explicar la secuencia efectiva en que fue creado el universo físico. Robert Grosseteste participó en esta empresa y en tres de sus tratados, Hexaëmeron, De luce y De Motu corporali et luce, abordó cuestiones relacionadas con la creación. En el fondo, los tres textos comparten un mismo objetivo: ofrecer un fuerte sustento metafisico-filosófico a las sagradas escrituras, específicamente a la narración del Génesis. En el Hexaëmeron este propósito se hace especialmente explícito. Alli Grosseteste explica y comenta detalladamente la narración de los primeros seis dias de la creación, sustentando el relato bíblico con elementos de la doctrina aristotélica y acudiendo a autores neoplatónicos, sobre todo Agustín de Hipona. Los tratados De luce y De Motu corporali et luce son mucho más breves en extensión pero ganan en claridad y precisión. El De Motu corporali et luce indaga por la primera causa del movimiento. Y el Tractatus de luce (traducido al inglés como On light) es mucho más ambicioso y presenta de manera sintética las posturas cosmológicas de Grosseteste. Fue escrito en la madurez intelectual del obispo, entre 1225 y 1230, y constituye una de las expresiones más originales de lo que se conoce como "metafisica de la luz"24. En seguida presentaremos los aspectos generales de la explicación que ofrece Grosseteste sobre el origen del cosmos. Tomaremos como texto base el tratado De luce, aunque ocasionalmente nos referiremos a otros.

El tratado De luce puede dividirse en dos partes. En la primera Grosseteste muestra que la luz es la primera forma corporal. En la segunda el obispo se encarga de ofrecer una narración plausible de la manera como tuvo origen el cosmos.

\section{IV.1. La luz, primera forma corporal}

De Luce comienza con la siguiente afirmación: "La primera forma corporal, que algunos llaman corporalidad, es en mi opinión la luz. Pues la luz por su

\footnotetext{
${ }^{24}$ La expresión "metafísica de la luz" hace referencia a un capitulo muy importante en la historia del pensamiento, que comprende algunos estudios y trabajos realizados desde la Antigüedad hasta antes del Renacimiento, en los que se otorgó a la luz, no en su sentido estrictamente físico sino en un aspecto metafísico y espiritual, el papel primordial en cuestiones relacionadas con la filosofia y la religión. La expresión fue acuñada por Clemens Baumker en el año 1916 (McEvoy, J., Robert Grosseteste, Oxford: Oxford University Press, 2000, p. 87).
} 
propia naturaleza se difunde a sí misma en todas direcciones de tal manera que un punto de luz produce instantáneamente una esfera de luz de cualquier tamaño, a menos que un cuerpo opaco se interponga en el camino" (De luce, p. 10).

Grosseteste hereda de la tradición árabe la noción de forma corporal ${ }^{25}$. Para el obispo, como para los filósofos árabes, la primera forma corporal constituye la forma común que comparten todos los cuerpos, precisamente en la medida en que son cuerpos. Ahora bien, los cuerpos están acompañados de la extensión tridimensional de la materia que les es propia. Decimos que algo es corpóreo cuando está extendido en las tres dimensiones. La primera tarea de Grosseteste, tarea que ya había sido adelantada por los filósofos árabes, especialmente Avicena y Averroes, consiste en mostrar que la primera forma corporal es la responsable de la extensión de los cuerpos y en explicar cómo esta consigue insuflar tridimensionalidad a la materia. La principal dificultad que advierte Grosseteste es que "tanto la corporalidad como la materia son en sí mismas substancias simples, carentes de dimensiones" (De luce, p. 10). Ninguna forma separada de la materia tiene extensión espacial y, del mismo modo, la materia desnuda, abstraida de todas las formas que la determinan, no se extiende en las tres dimensiones. Si la corporalidad y la materia son substancias simples, carentes de dimensiones, ¿cómo entonces se generan a partir de ellas los cuerpos, cuya propiedad esencial es la extensión tridimensional? Grosseteste propone la existencia de un principio activo intrínseco a la corporalidad, gracias al cual esta, siendo simple, puede dar origen a la extensión tridimensional de la materia. El razonamiento completo que lo lleva a postular esta hipótesis y a atribuir la presencia de un principio inherente a la corporalidad es el siguiente: todos los cuerpos se originaron solamente a partir de materia primera y forma

\footnotetext{
25 El concepto de forma corporal fue una modificación de la doctrina aristotélica introducida por los intelectuales árabes. Aristóteles concebía los objetos corpóreos como un compuesto de materia y forma. La forma, para él, consistía en todas aquellas propiedades que dotaban de identidad a una cosa, en tanto que la materia era el sustrato de esas propiedades. El estagirita introdujo además la noción de "materia primera", refiriéndose a una materia sin cualidad alguna, una materia que no aloja ninguna forma, pero que era informada por las formas de las cualidades elementales (caliente, frío, húmedo, seco) para dar origen a los cuatro elementos. Avicena y Averroes advirtieron una dificultad en las enseñanzas de Aristóteles: Si la materia primera era en sí misma carente de toda cualidad, ¿cómo era posible entonces que fuera susceptible de recibir las formas elementales? A juicio de los sabios árabes era necesario un paso intermedio: antes que la materia primera fuera afectada por las formas elementales, debía extenderse en las tres dimensiones para así poder alojarlas. Con esta idea en mente idearon el concepto de forma corporal. La forma corporal, para ellos, era la primera forma de los cuerpos, aquella que dotaba de corporalidad a la primera materia para que, extendida en el espacio, pudiera recibir ulteriores formas (Lindberg, D., Los inicios de la ciencia occidental, p. 359).
} 
primera. Se sabe, además, que el ser corpóreo de los cuerpos va acompañado necesariamente de la extensión tridimensional de la materia. Por lo tanto, materia y forma corporal primeras deben ser también el origen de la extensión de la materia. Sin embargo, estas son en sí mismas substancias simples, carentes de dimensiones. Debe haber, propone el obispo, algún principio activo intrínseco en ellas a partir del cual tome lugar la extensión tridimensional de la materia. Ese principio debe encontrarse o bien en la materia primera o bien en la forma primera. Pero la materia es en sí misma pasiva, inerte, incapaz por sí misma de cualquier actividad. De lo que se sigue, pues, que aquel principio activo debe hallarse en la primera forma, en la corporalidad ${ }^{26}$.

La segunda tarea de Grosseteste consiste en mostrar que la primera forma corporal es, en efecto, la luz. Este es el centro de su propuesta. Sobre la idea de que la primera forma debe poseer un principio activo que extienda la materia en las tres dimensiones, queda por resolver la pregunta específica acerca de qué es exactamente la primera forma: ¿qué es aquello que, siendo simple, se puede extender en las tres dimensiones? El obispo avanza en sus razonamientos y advierte que ese es precisamente el rasgo característico de la luz: generar tridimensionalidad a partir de aquello que carece de dimensiones, extendiéndose y multiplicándose hacia todas partes. "La luz posee [escribe Grosseteste] por su propia naturaleza la función de multiplicarse y difundirse a sí misma instantáneamente en todas direcciones" (De luce, p. 10). De un punto de luz, como tal simple y no extendido en el espacio, la luz genera, por un principio activo inherente a ella, una esfera luminosa, extendida en las tres dimensiones propias de los cuerpos. Esto lleva a Grosseteste a afirmar que la luz ha de ser la primera forma corporal, la luz ha de ser la corporalidad.

\section{IV.2. La creación del cosmos}

Las páginas sucesivas del De luce ofrecen una narración plausible del origen del cosmos. En el principio fue la luz, diría el obispo. Pero no en un sentido metafórico. La creación original de Dios debió consistir, en efecto, en un único punto de luz. Ese punto de luz -al que en adelante llamaremos luz primordial, luz primera o luz original-, era la primera forma corporal, la luzforma, y contenía dentro de sí la primera materia; era el compuesto de primera

\footnotetext{
${ }^{26}$ Riedl (Riedl, C., Introduction, en: Grosseteste, R., On light, Milwaukee: Marchette University Press, 2008, p. 3) traductor de la edición inglesa del tratado De luce, enfatiza sobre este aspecto al apuntar que en la metafísica de Grosseteste la función de la forma es completar, perfeccionar y actualizar la materia.
} 
materia y primera forma. Por su propia naturaleza, por su potencia para generar una esfera luminosa a partir de un punto, el punto original se multiplicó y difundió en todas direcciones: "así la luz [dice Grosseteste], que es la primera forma creada en la primera materia, se multiplicó a sí misma por su propia naturaleza un número infinito de veces hacia todos lados y se expandió uniformemente en todas direcciones" (De luce, p. 11). En un pasaje del Hexaëmeron, Grosseteste explica la manera como ocurre la multiplicación: "la luz que es primera por naturaleza genera la luz que le sigue y la luz que es generada al mismo tiempo llega al ser, existe y genera la luz que a continuación le sigue, y la siguiente luz hace lo mismo para la luz que le sigue: y así en adelante. Esta es la razón de por qué en un instante un punto de luz, puede llenar una esfera completa con su luz" (Hexaëmeron, II, X, 1). La expansión corresponde, pues, a una secuencia de puntos de luz que se generan continuamente, uno después de otro y a partir de otro. El punto original generó nuevos puntos de luz a su alrededor, en todas direcciones, y estos, a su vez, del mismo modo que su antecesor, inmediatamente vinieron a la existencia generaron otros puntos, que también se multiplicaron como los anteriores, y así indefinidamente, en una especie de gran expansión, un big-bang de luz. Pero en la creación la luz no se expandió sola. Grosseteste continúa: "De esta manera la luz procedió en el principio de los tiempos a extender la materia, que no podía ser dejada atrás, [y lo hizo] al arrastrarla consigo misma en una cantidad del tamaño del universo material" (De luce, p. 11). Como el punto de luz original contenía dentro de sí la primera materia, la luz la arrastró con ella; al multiplicarse, la multiplicó, y al difundirse, la difundió. La primera materia, entonces, como halada por la luz, sin separarse de ella, se extendió también en las tres dimensiones hasta formar la cantidad finita del universo material.

Grosseteste hace una aclaración acerca de la multiplicación que tuvo lugar en aquellos primeros instantes de la creación. No pudo ser una multiplicación finita, sostiene acudiendo a la autoridad de Aristóteles, pues "la multiplicación de un ser simple un número finito de veces no produce una cantidad" (De luce, p. 11) 2 $^{27}$ Una secuencia finita de puntos, como tal simples, sin dimensiones, no originaría dimensión alguna: "[S]in embargo, [continúa

\footnotetext{
${ }^{27}$ En este pasaje Grosseteste se apoya en la autoridad de Aristóteles, refiriendo un pasaje de De Caelo et mundo. Aunque el obispo no menciona explícitamente qué fragmento de Aristóteles está siguiendo, Riedl señala que se trata de III, 1, 299a, 25-30, donde el Estagirita discute la tesis según la cual los objetos sensibles son generados por planos, los planos por líneas y las líneas por puntos.
} 
el obispo] la multiplicación de un ser simple un número infinito de veces debe producir una cantidad finita" (De luce, p. 11). Grosseteste tiene en mente lo que ocurre con las fuentes de luz, que, multiplicándose a su alrededor, dan origen a una esfera luminosa de extensión finita. El punto original de luz se multiplicó instantáneamente un número infinito de veces, multiplicando la materia dentro de sí, y como resultado se generó una cantidad finita extendida en las tres dimensiones: la cantidad del universo material. La forma que adoptó este primer cuerpo creado no pudo ser arbitraria; al contrario, por la naturaleza de la multiplicación de la luz, esa cantidad tuvo que abrigar la forma de una esfera perfecta. De ahí la esfericidad del cosmos. Pero esta no es la única consecuencia del modo como se propaga la luz. En las vecindades de una fuente luminosa, la luz circundante producida a partir de la multiplicación de la fuente parece debilitarse cuando se aparta de su origen, pierde intensidad progresivamente, hasta que finalmente desaparece por completo. Esta característica tiene una importante implicación en la narración ofrecida por Grosseteste en el De luce: "Digo que la luz [continúa el obispo] a través de la infinita multiplicación de sí misma de manera homogénea en todas direcciones extendió la materia hacia todos lados en la forma de una esfera y, como consecuencia necesaria de esta extensión, las partes exteriores de la materia están más extendidas y más rarificadas que las partes de adentro, que están más cercanas al centro" (De luce, p. 13). En el proceso de multiplicación la luz se debilitó progresivamente, se hizo menos intensa, menos fuerte, y como arrastraba consigo la primera materia, las partes más extendidas y alejadas del punto original se tornaron cada vez menos densas, más rarificadas. La cantidad finita en forma esférica originada a través de la multiplicación infinita no resultó por tanto uniforme en cuanto a su densidad. Las partes más cercanas al centro fueron más densas en la medida que la luz cercana a la fuente era más intensa, y las partes más alejadas, alli donde la luz perdía intensidad y se desvanecía, resultaron menos densas: "[L]as partes más exteriores [de la cantidad generada, asegura Grosseteste] estarán rarificadas en el más alto grado, [en tanto que] las partes interiores tendrán la posibilidad de rarefacción adicional" (De luce, p. 13). El resultado de la multiplicación fue un cuerpo no homogéneo en cuanto a su densidad, del mismo modo en que la esfera luminosa generada por una fuente de luz no es homogénea en cuanto a su intensidad. El límite del cuerpo esférico generado por la luz primera corresponde al momento en el proceso de multiplicación en el que la densidad no puede ser menor y las partes más exteriores no son susceptibles de expansión adicional. 
Citemos nuevamente a Grosseteste: "De esta manera la luz, al extender la materia en forma de una esfera, y al rarificar sus partes exteriores al más alto grado, actualizada completamente en las partes más exteriores la potencialidad de la materia, deja a esta materia [la que se ubica en las partes más exteriores] sin ninguna potencia para impresión adicional" (De luce, p. 13). Allí donde la densidad llega su nivel ínfimo y donde la materia está completamente actualizada y no es susceptible de mayor extensión, se forma el primer cuerpo: el firmamento. Acerca de este Grosseteste dice que "es perfecto, porque no tiene nada en su composición excepto primera materia y primera forma" (De luce, p. 13). A partir del firmamento toma lugar otro proceso de generación y multiplicación. Como cuerpo ya constituido, el firmamento tiene una luz propia (lux) y a partir de esta se origina otra luz (lumen) por una nueva multiplicación. La fuente del nuevo proceso de generación no es ahora la luz primigenia, sino la luz del firmamento. ¿En qué dirección parte ahora la luz generada? No puede hacerlo hacia afuera, pues el firmamento es el limite del cosmos y nada hay más allá de él. La luz emanada del firmamento parte desde cada punto de aquel con dirección hacia el centro. Por un mecanismo que no es del todo claro en la explicación del obispo, esta luz interactúa con la materia ubicada al interior, aquella que es susceptible aun de mayor expansión, y al hacerlo, la expande nuevamente hasta que sus partes llegan a ser más rarificadas. En esta nueva expansión se origina la esfera celeste más cercana al firmamento. El proceso se repite para conformar las nueve esferas celestes y posteriormente las cuatro esferas de los elementos.

\section{Grosseteste: El neoplatonismo en la cosmología medieval}

Se puede ver que el sistema cosmológico de Grosseteste es de notable sincretismo. No debemos ver en ello la expresión de un error inaceptable; al contrario, en muchos sentidos es una virtud. El sincretismo permite desarrollar sistemas novedosos enriquecidos por distintas tradiciones. En la cosmología de Grosseteste encontramos principalmente tres posturas: la doctrina aristotélica, el pensamiento neoplatónico y el creacionismo cristiano. Grosseteste concibe un mundo creado por Dios, en este sentido es creacionista; la estructura y organización de ese mundo son tales como asegura la doctrina aristotélica, en este sentido es aristotélico; y el proceso mediante el cual fue creado es un proceso que incorpora en sus puntos fundamentales reflexiones neoplatónicas, por eso también es neoplatónico. Sin embargo, de las tres principales tradiciones que 
alimentan la cosmología del obispo es particularmente relevante la acentuada influencia del neoplatonismo en el problema de la creación del cosmos.

He reservado la última sección del texto para hacer explícitas las notables correspondencias -que ya resultarán evidentes para el lector- entre la cosmología de Grosseteste y las posturas de la escuela neoplatónica, particularmente las posturas relacionadas con la metafisica del Uno. Las tres principales correspondencias que desarrollaré en mi análisis serán: la unidad del principio, el proceso de generación y la unidad del sistema. En estos tres puntos encontramos con toda su fuerza el neoplatonismo en la cosmología de Grosseteste.

\section{V.1. La unidad del principio}

Los primeros pasajes del De luce parecen sugerir la presencia de dos principios a partir de los cuales tuvo origen el cosmos: la primera materia y la primera forma. No tendría sentido entonces afirmar que la cosmología de Grosseteste, en su propósito fundamental de explicar el surgimiento del mundo, toma como punto de partida la existencia de un único principio. Sin embargo, como expondré a continuación, Grosseteste adopta una posición según la cual el principio que dio origen al universo en toda su extensión corpórea es un principio uno y único. Para ello, explicaré los conceptos de materia primera y forma primera. Mostraré que aunque se trate de dos conceptos opuestos, en la metafisica de Grosseteste podemos encontrar un principio de inseparabilidad entre materia y forma primeras que reduce a un origen unitario el surgimiento del cosmos.

La influencia de la filosofia de Aristóteles en el pensamiento de Grosseteste corrió por cuenta de varios caminos. Uno de ellos fue la metafísica. En la metafísica de Aristóteles las sustancias están compuestas de materia y forma. En principio, Grosseteste adopta una posición muy parecida. En sus propias palabras: "nada existe en común en todo cuerpo sino la materia y la forma primeras" (De motu corporali et luce, p. 41). A partir de ellas tienen lugar las otras características que reconocemos propias de los cuerpos. Incluso características como la extensión y la magnitud, que suponemos inseparables de los seres corpóreos, tienen lugar a partir de la primera materia y la primera forma. Sin embargo, la similitud de Grosseteste con la doctrina aristotélica no es completa y hay algunos aspectos en los que el obispo se aparta y adopta nuevas interpretaciones o utiliza los conceptos fundamentales del aristotelismo de manera distinta. Esto ocurre con las nociones de materia, forma y sustancia. Para Aristóteles las sustancias solo tienen lugar alli donde participan 
conjuntamente materia y forma. Lo que está privado de alguno de estos dos elementos no es una sustancia. Cuando a la mente de un arquitecto viene la idea de una nueva construcción, por ejemplo, esa idea, tomada en sí misma, en tanto que no está aún materializada, no sería una sustancia. La posición de Grosseteste es diferente. Para él, materia y forma primeras son en sí mismas sustancias simples -"tanto la corporalidad como la materia son en sí mismas sustancias simples" (De luce, p. 10)- y, aunque no sean cuerpos, aunque no tengan dimensiones, tienen cierto grado de realidad, cierta sustancialidad, una sustancialidad simple de grado ínfimo, menor que la sustancialidad de cualquiera objeto de los que conforman el cosmos. Las sustancias corresponderían a un género más amplio que el de los seres sensibles, un género que abarcaria los seres sensibles, por supuesto, pero también la forma y la materia primeras. Sobre este punto hace énfasis Riedl en su comentario a Grosseteste: "El principal punto de divergencia es que para Grosseteste la materia no es pura potencia, como es para Aristóteles, sino que posee por su propio derecho cierta mínima realidad. De esta manera, Grosseteste habla de materia como una substancia"28.

La sustancialidad entonces no es posterior a la materia y a la forma, como pensaría un aristotélico ortodoxo, sino que "ser sustancia" es un predicado que se puede otorgar tanto a la una como a la otra, a la materia sin forma y a la forma sin materia, o a las dos en conjunto (las genuinas sustancias aristotélicas). Ahora bien, que se tenga a la forma y a la materia como sustancias por propio derecho, que se les confiera una minima realidad, como afirma Riedl, dista mucho de suponer que la forma y la materia, aisladas una de otra, tengan existencia efectiva en el mundo físico. La materia, de hecho, siempre está dispuesta según una forma determinada -presta a recibir otras formas, pero nunca como materia desnuda, pura-y del mismo modo nunca advertimos en el mundo formas desprovistas de materia. En ello, el pensamiento de Grosseteste se ajusta nuevamente a uno de los puntos fundamentales de la metafisica aristotélica: todo ser sensible está compuesto de materia y forma. En un pasaje del De luce podemos leer lo siguiente: "La forma no puede abandonar la materia, porque es inseparable de ella, y la materia en sí misma no puede ser desprovista de forma" (De luce, p. 10). Así las cosas, en la metafísica de Grosseteste, metafisica sobre la cual se construye su sistema cosmológico, encontramos un principio de inseparabilidad según el cual en la naturaleza, en el mundo

${ }^{28}$ Riedl, C., o.c., p. 3. 
de los seres sensibles, materia y forma no tienen existencia a menos que estén juntas, aun si pueden pensarse como substancias separadas, independientes, con un grado ínfimo de realidad.

El orden de la presentación que Grosseteste ofrece en el De luce por momentos puede llevarnos a pensar que son dos los principios desde los cuales tuvo origen el cosmos, que la materia sin forma existía con anterioridad y luego, por intervención divina, fue informada por la luz para extenderse en las tres dimensiones -considérese, por ejemplo, el pasaje "Así la luz, que es la primera forma creada en la primera materia..." (De luce, p. 11)-. Pero, aunque el discurso tenga ese orden y con frecuencia aparezcan en el desarrollo de la narración los conceptos de materia en sí misma o de forma en sí misma, no debemos leerlo como si describiera una distinción real de las cosas. En la cosmología del obispo, las consideraciones y reflexiones acerca de la materia en sí misma, señala Oliver ${ }^{29}$, son meramente conceptuales y no entrañan un compromiso ontológico. La distinción materia en sí misma y forma en sí misma vendrían a ser lo que Descartes denominaba una distinción de razón.

Atendiendo a esta inseparabilidad -"la forma no puede abandonar la materia, porque es inseparable de ella, y la materia en sí misma no puede ser desprovista de forma" (De luce, p. 10)-, podemos recuperar la unidad del principio a partir del cual tuvo lugar el mundo físico. En el sentido estrictamente ontológico, no hay dualidad en la génesis del cosmos. Aunque materia primera y forma primera se puedan pensar de manera independiente y en efecto cada una sea una sustancia, aun así ellas conforman un único ser en el mundo sensible: la luz primordial. No debemos confundir esa luz primordial con la luz-forma. La luz primordial es el compuesto de luz-forma y primera materia. En el sistema cosmológico de Grosseteste encontramos, pues, que Dios no crea la primera materia y la primera forma de modo independiente, sino que al crear una crea la otra. En el Hexaëmeron, el obispo afirma de manera contundente: "Dios, el creador, no hizo primero una materia sin-forma y después de un tiempo, como si fuera una idea tardía, atendiendo la orden de alguna naturaleza, la formó; no, él la creó al formarla y la formó al crearla" (Hexaëmeron, II, V, 5). De este modo, concluimos que en el mundo físico, en el cosmos creado, la luz primordial es una y es el principio del cosmos, así como el Uno en la metafísica de Plotino era uno y principio de la realidad.

${ }^{29}$ Oliver, S., "Robert Grosseteste on Light, Truth and Experimentum", en:Vivarum, v. XVII, 2 (2004), p. 155. 
El punto primordial de luz a partir del cual se originó el cosmos comparte muchas caracteristicas que habiamos descrito cuando enunciamos los predicados del Uno:

(1) La luz primordial es principio. A partir de ella y gracias a ella, por su potencia para generar una esfera a partir de un punto, multiplicándose a sí misma y extendiéndose en las tres dimensiones, se originan todos los cuerpos. Nada hay en el cosmos anterior a ese primer punto de luz. Todos los seres sensibles, por disimiles que sean, desde el firmamento hasta los habitantes de la región sublunar, se generaron en algún momento de la expansión original o de las contracciones y nuevas expansiones que enseguida tuvieron lugar.

(2) La luz primordial es única. Aunque no haya en Grosseteste un argumento a priori que nos permita argumentar a favor de la unicidad del principio, aun así este es el punto de partida del tratado De luce y es el soporte tácito sobre el que reposa la estructura aristotélica del cosmos que asume el obispo. Un único punto de luz es lo que asegura la organización de esferas concéntricas que conforman el universo físico.

(3) La luz primordial es causa. Por su propia naturaleza, la luz se multiplica en todas las direcciones y puede generar una esfera luminosa a partir de un origen puntual. Esa capacidad de extenderse en las tres dimensiones y de arrastrar consigo la materia es la que da origen al cosmos. La luz es el principio activo de generación; es la potencia en constante realización que extiende la materia en su dimensión corpórea. Los procesos subsiguientes de generación, aquellos que tienen lugar a partir de la luz del firmamento y que originan las esferas celestes y las esferas de los elementos, dependen, en primer término, de la luz primordial.

(4) La luz primordial es perfecta. En varios pasajes de su obra Grosseteste exalta la naturaleza de la luz. Dice de ella que es la forma "más exaltada y de esencia más noble y excelente que la de todas las cosas corporales" (De luce, p. 10). No cabe duda que el obispo, como heredero y continuador de la tradición clásica y medieval, recoge y asimila las opiniones que tenían otros grandes filósofos -caso paradigmático Agustín de Hipona-, atribuyéndole a la luz bondades físicas y metafísicas.

(5) La luz primordial es simple. Dicha simplicidad del punto de luz primordial debemos entenderla de manera estrictamente geométrica: simplicidad como la carencia de dimensiones. La luz primordial es puntual y, como tal, simple. Aunque pueda parecer contradictorio pensar que ese punto sea compuesto -materia y forma primeras- a la vez que simple, nos dice Grosseteste: "este tipo 
de compuesto [el de materia y forma] no se opone a lo simple" (De generatione stellarum, p. 82). El compuesto de materia y forma es un tipo de composición conceptual que, como dijimos, no supone un estado efectivo de cosas.

La luz primordial también (6) permanece. Genera, es verdad, pero lo hace sin fragmentarse o dividirse en la luz emanada; lo hace permaneciendo en sí misma por multiplicación de su propia naturaleza. Ciertamente (7) engendra, gracias a su potencia autogeneradora, y más que eso, engendra incesantemente, produciendo infinitas copias de sí. Si encuentra un limite es por la naturaleza de su multiplicación, por la pérdida de intensidad de las luces emanadas; pero la generación de copias suyas se prolonga infinitamente. Del mismo modo (8) es omnipresente, ya que ella misma, o mejor, las copias que engendra, conforman todo el material corpóreo del que está hecho el cosmos. No hay objeto sensible en el que la luz primordial, por cuenta de alguna de sus copias, no esté presente. Y también podemos decir que (9) es trascendente, pues aunque el cosmos todo esté formado gracias a su actividad generadora, ella misma, la luz primordial, ese compuesto simple primigenio de luz y forma primeras, no es ninguno de los objetos del cosmos, es anterior a todo cuerpo.

\section{V.2. El proceso de generación}

Recordemos que la simplicidad de la primera materia y la primera forma -componentes de la luz primordial, como hemos insistido, acarreaba un importante problema en el sistema cosmológico del obispo. Grosseteste aceptaba tres premisas fundamentales: (1) todo cuerpo tiene extensión y magnitud; (2) la extensión y la magnitud son propiedades derivadas de la primera materia y la primera forma; y finalmente, (3) materia y forma primeras son en sí mismas sustancias simples, carentes de dimensiones y de cualquier tipo de extensión o magnitud. Como vimos, esto obligaba a concluir que, toda vez que la materia es pasiva, la extensión y la dimensionalidad de los cuerpos debian generarse necesariamente a partir de la simplicidad de la primera forma. Y aquí se presentaba precisamente la dificultad: ¿cómo a partir de lo simple se genera lo extenso? ¿Cómo desde un punto tiene lugar la cantidad? ¿Cómo se origina la dimensión desde lo carente de dimensiones? A quien ha seguido cada parte del presente texto este problema no debe parecerle extraño; al contrario, luce bastante familiar. Una de las cosas que he querido mostrar a lo largo de la presentación es que en la cosmología de Grosseteste encontramos una formulación renovada del problema que Plotino planteó y resolvió a propósito de la generación de lo múltiple a partir del Uno: ¿cómo a partir del Uno se genera 
lo múltiple? La solución al nuevo problema también guarda estrechas relaciones con la teoria de la doble actividad de Plotino. De lo que se trata ahora no es tanto de indagar por las emanaciones del Uno a partir de las cuales se engendra lo múltiple, sino de profundizar en los mecanismos de la luz primordial para producir extensión y cantidad desde su simplicidad.

Antes de recuperar la solución de Grosseteste al problema sobre la generación de la extensión a partir de lo carente de dimensiones, y para resaltar aun más sus similitudes con posturas neoplatónicas, quisiera retomar parte de las explicaciones de Plotino. En un brillante y elocuente pasaje del primer tratado de la quinta Enéada, Plotino pregunta: “¿Y cómo hay que pensar y qué hay que pensar (que vino a la existencia) alrededor de aquel mientras permanece él mismo?" (V, 1, 6, 27-29). A ello responde: "Una radiación circular emanada de él... pero emanada de él mientras él permanece, al modo del halo del sol que brilla a su alrededor como aureándolo, brotando perennemente de él mientras él permanece" (V, 1, 6, 29-33). Plotino usa la metáfora del sol para explicar cómo la primera potencia engendra todo cuanto existe. Como ocurre con el sol, que emana una radiación circular en derredor suyo, así también el Uno permanece en su propia índole mientas emana una especie de halo circular que lo rodea. La referencia a la circularidad de las emanaciones producidas desde el Uno no es accidental. En el capítulo siete de la misma Enéada y en el mismo tratado, Plotino compara la relación que guardan la multiplicidad y el Uno con la que mantienen un círculo y su centro. Dice el filósofo: "El círculo es divisible por naturaleza, mientras que el centro no lo es" (V, 1, 7, 2-4). La relación que hay entre el centro y el círculo es "como de lo indivisible a lo divisible" (V, 1, $7,13)$. Lo mismo ocurre en la relación entre el Uno y la multiplicidad: el Uno es indivisible en tanto que la multiplicidad es divisible. En la cosmología de Grosseteste tenemos una situación parecida: la luz primordial, como punto que contiene en sí la primera materia y la primera forma -y ya se vio que este tipo de compuesto no afecta la simplicidad- es indivisible, mientras que los cuerpos, por cuanto tienen extensión, son divisibles.

Las primeras páginas del tratado De luce contienen un ingenioso intento por responder a la pregunta acerca de cómo lo indivisible genera lo divisible. Aquel tránsito debía ser dado gracias a la forma primera, "pero una forma que es en si misma simple y sin dimensiones, [sostiene el obispo] no podria introducir dimensión en todas las direcciones a la materia, que es igualmente simple y sin dimensiones, excepto multiplicándose y difundiéndose a sí misma en todas las direcciones y así extendiendo la materia en su propia difusión" (De luce, 
p. 10). En estrecha relación con las analogías que usa Plotino para explicar la generación de la multiplicidad a partir del Uno, Grosseteste encuentra en la luz ese poder, esa potencia para multiplicarse y difundirse en todas direcciones y favorecer de ese modo el tránsito desde lo puntual e indivisible, el punto original de luz, hacia los cuerpos y la divisibilidad que les es propia. Entre los seres, un punto de luz es aquello que tiene la capacidad para, siendo simple, generar una cantidad (De luce p. 10), para generar una esfera luminosa en sus alrededores, y lo hace sin fragmentarse, sin disolverse en la luz emanada, posibilitando con ello el surgimiento de la extensión, de lo divisible y de lo dimensionado, aunque el origen mismo de esa extensión sea lo opuesto, lo puntual, lo indivisible y lo carente de dimensiones. La luz, afirma Grosseteste, "hace surgir la primera materia corporal en la dimensión corpórea y lleva la materia a su máxima extensión y dilatación" (De operationibus solis, p. 156).

La propiedad multiplicadora de la luz está perfectamente descrita en el siguiente pasaje: "La naturaleza de la luz es tal que se multiplica a sí misma en todas direcciones. Ella tiene lo que podría llamarse autogeneración de su propia sustancia. Pues por su naturaleza la luz se multiplica a sí misma en todas direcciones por generación de sí misma, y genera todo el tiempo que ella existe. Por esta razón llena instantáneamente el lugar que la rodea: la luz que es primera por naturaleza genera la luz que sigue a ella, y la luz que es generada al mismo tiempo llega a ser, y existe, y genera la luz próxima que le sigue, y la siguiente luz hace lo mismo por la luz que le sigue; y así sucesivamente" (Hexaëmeron, p. 97).

La metafísica de la multiplicación de la luz que Grosseteste desarrolla en sus tratados cosmológicos refleja los elementos centrales de la teoría de la doble actividad de Plotino. Ajustados ahora a la cosmología del obispo, podemos afirmar que la luz primordial posee dos actividades. En un sentido, al tener existencia efectiva a partir del momento que Dios la creó, la luz primordial posee la primera actividad, la actividad propia de la esencia, y que, en términos de Plotino, es la cosa misma en acto, el punto original de luz existiendo. En otro sentido, al emitir o emanar otra luz a sus alrededores multiplicándose sin merma de su propio ser, la luz primordial posee la segunda actividad, la actividad derivada de su esencia. Esta segunda actividad de la luz primordial podemos concebirla, igual que en la teoría de Plotino, como una copia o imagen de la primera, toda vez que, como escribe Grosseteste, esta luz segunda, por llamar de algún modo a la luz generada en las vecindades más inmediatas de la luz primordial, se obtiene por autogeneración de la propia sustancia de la 
luz primera. Tenemos entonces que la luz emanada comparte la sustancia de la luz primordial; la luz emanada es semejante a su fuente. Y del mismo modo todas las luces generadas a continuación son semejantes a la luz primera, pues estas se originan por autogeneración de luces anteriores que, a su vez, y en último término, heredan la sustancia de la luz primordial. Pero aunque la luz emanada participa de la sustancia de la luz primera, no por ello Grosseteste las concibe como una sola. La luz segunda es otra luz, distinta de la primera, una luz menos intensa. En resumen, la luz primordial genera copias de sí misma, pero sin dejar de ser ella; no se fragmenta sino que se multiplica y no abandona su naturaleza.

El proceso de multiplicación de la luz en la cosmología de Grosseteste respeta también las dos características de las emanaciones plotinianas: la productividad de lo perfecto y la degeneración progresiva. La luz generada, cuando llega a ser y existe, recuperando las palabras de Grosseteste, genera la luz próxima, esto es, cuando se constituye como luz, produce una luz siguiente. Pero la intensidad se pierde progresivamente a medida que las réplicas se alejan del punto original y la materia que la luz arrastra en su multiplicación se torna cada vez menos densa. Esta degeneración de la intensidad, traducida en disminución de la densidad de la materia, es la que determina, alli en el nivel ínfimo, el primer cuerpo creado. Si en Plotino la incesante cadena productora que empieza en el Uno tiene su fin en la materia, la negación absoluta, en la cosmología de Grosseteste el fin de la infinita multiplicación que tiene lugar desde la luz primordial se encuentra en el firmamento, donde la materia ha alcanzado su máxima extensión y no es susceptible de expansión adicional.

Las relaciones entre el proceso de generación entre el sistema de Plotino y la cosmología de Grosseteste no acaban ahí, pues los procesos ulteriores de generación, aquellos que tienen lugar a partir del firmamento como cuerpo constituido, también presentan las características de las emanaciones plotinianas. El firmamento es perfecto en la medida que la materia en él está completamente actualizada. Tiene una luz propia, heredada de la luz primordial -a la que Grosseteste refiere usando por vez primera en su texto el término lux-, y de esta emana otra luz -a la que llama lumen, para distinguirla de la primera- que se "expande" hacia el interior del cosmos, multiplicándose en el medio para interactuar con la materia ubicada cerca al centro y expandirla nuevamente. Al hacerlo, la materia se perfecciona, se actualiza, y tiene lugar la esfera celeste más cercana al firmamento; y esta, por su parte, como cuerpo que ha alcanzado así su grado de perfección, es el manantial de un nuevo 
proceso de generación. La diferencia aquí entre una actividad interna, lux, luz en el cuerpo, y una externa o emanada, lumen, luz en el medio, es explícita. La productividad de lo perfecto se evidencia en el hecho de que solo cuando la materia de las esferas celestes y de las esferas de los elementos ha alcanzado su mayor actualización posible, solo entonces comienza un nuevo proceso de generación. Y la degeneración progresiva se advierte en la jerarquía de las esferas generadas. El firmamento es lo más perfecto -la materia en él está completamente actualizada-, a continuación están las esferas celestes, donde la materia es sutil pero no tanto como en el firmamento, y finalmente se hallan las esferas de los elementos, en donde la materia es mucho más densa.

\section{V.3. Unidad del sistema}

La unidad del sistema es una de las características principales de la filosofia de Plotino. En la metafísica del Uno todas las imágenes o copias emanadas a partir de él participan en algún grado de la naturaleza de su progenitor. Una vez alcanzan su estado de perfección, las copias engendran nuevas copias, formando cadenas de generación que se prolongan constantemente. Es un sistema dinámico de ininterrumpida generación. La multiplicidad de seres se origina como resultado de este vasto despliegue. Pero lo que queremos resaltar es que, pese a aquella pluralidad, cualquier ser, sin importar si es la Inteligencia o algún objeto sensible del Alma inferior, si ha alcanzado su grado de perfección o no, ese ser se ubica en algún punto de alguna cadena productora, y en esa medida, por vía de los intermediarios, que pueden ser muchos o ninguno -caso este reservado a la Inteligencia, que contempla directamente al Uno-, participa de la unidad primordial de la que toma su existencia. Esta unidad del sistema, entendida como participación de la Unidad, aparece de manera explícita en el siguiente pasaje: "Si se da algo a continuación del Primero, es necesario que o provenga inmediatamente de aquel o se remonte a aquel a través de los intermediarios, y que exista un orden de Segundos y Terceros en que uno -el Segundo- se remonte el Primero y el Tercero al Segundo" (V, 4, 1, 1-5).

Podemos imaginarnos el proceso de generación en el sistema metafísico de Plotino a la manera de una gran cascada que no para de fluir, de la que siempre mana agua, agua que se ensancha y diversifica en su caída en múltiples bifurcaciones. El único origen de la cascada es el Uno, y su continuación, la multiplicidad de seres. La disposición de los seres es jerárquica: los que están ubicados en las vecindades del Uno, cercanos a la fuente, son los seres más perfectos, en tanto que los seres que están más abajo, gozan de menor grado 
de perfección. Sin embargo, y en esto hay que ser enfáticos, todos los seres, cualquiera sea su lugar en la jerarquía, participan de la unidad primordial de la que reciben directa o indirectamente su existencia. Esta es la propiedad común: todo ser, en tanto ser, participa del Uno en algún grado -“todos los seres por la unidad son seres" (VI, 9, 1, 1-5)-. La ontología plural se unifica entonces en la medida que todo ser posee en algún grado al Uno dentro de sí.

En la cosmología de Grosseteste encontramos una unificación similar: todos los cuerpos, en la medida que son cuerpos, participan de la luz primordial. En uno de sus tratados el obispo escribe: "[N]ada existe en común en todo cuerpo sino la materia y la forma primeras" (De motu corporali et luce, p. 41). Verdad es que la narración del De luce describe claras diferencias entre los cuerpos creados -por ejemplo, el firmamento, el cuerpo más perfecto, es diferente de todos los demás, pues la materia en él está completamente actualizada-, verdad es que Grosseteste acepta, de la mano de una estructura del mundo físico como enseñaba Aristóteles, la división entre cuerpos corruptibles e incorruptibles, sublunares y celestes; pero estas diferencias, y aquí el obispo se aparta de su maestro el Estagirita, son para Grosseteste diferencias de grado, específicamente del grado de actualización de la materia que conforma los seres sensibles o del nivel que ocupa esta en la expansión esférica a partir de la luz primordial. Ya vimos que la luz-forma actualizaba la primera materia en su expansión, insuflando en ella la tridimensionalidad, y a medida que la multiplicación se prolongaba, apartándose del punto original, la materia perdía densidad y se hacía más rarificada. El hecho central es que todo cuerpo del cosmos, en tanto cuerpo, esto es, en tanto tiene extensión, recibe su tridimensionalidad por cuenta de la multiplicación de la luz primordial. No importa en qué posición se encuentre con respecto al punto primero de luz, no importa si es celeste o sublunar, la materia extensa que lo compone fue generada en algún momento gracias a la multiplicación de la luz primera, que autogenera su propia sustancia y por ello está presente, por vía de sus copias, en el cosmos todo y en cada ser corpóreo en particular. Si la materia de la que está compuesto un cuerpo es muy densa -como podría decirse de una roca, por poner el caso, en donde predomina la tierra-, esa materia fue generada en las regiones más cercanas de la luz primera, en las copias iniciales que aquel punto hizo de sí mismo, y tiene la potencia de expandirse más; pero si, por el contrario, la materia que conforma el cuerpo está enrarecida, esta se originó en los últimos niveles de la multiplicación de la luz primordial, y seguramente el cuerpo se contará entre los objetos celestes. En cualquier caso, todos los seres participan de la luz 
primordial de la que obtuvieron su existencia como cuerpos, y las diferencias observadas responden no tanto a naturalezas opuestas como al lugar que ocupan en la multiplicación de la luz primera. En la cosmología de Grosseteste podemos decir: todos los cuerpos por la luz primordial son cuerpos.

\section{Conclusiones}

Hemos visto las relaciones y correspondencia de la filosofia de Plotino con la cosmología de Grosseteste. Explicamos algunos aspectos de la metafisica del Uno, entre ellos consideramos la solución al problema de la generación de lo múltiple a partir de la unidad primordial; enseguida vimos cómo ese problema tomó nuevos aires en el pensamiento de Grosseteste con relación al problema de la creación del cosmos. También detallamos tres puntos notables de la relación entre el sistema metafísico de Plotino y la cosmología del obispo: la unidad del principio, los mecanismos de generación y la unidad del sistema. No obstante, como parte final del texto, quisiera mencionar una importante restricción de la tesis que he pretendido defender. En el sistema de Plotino, el Uno es principio absoluto de todo cuanto existe, de todos los seres, de los sensibles, aquellos del Alma inferior, y los no sensibles. La luz primordial de la cosmología de Grosseteste, en cambio, es principio relativo de todos los cuerpos y su potencia como ente generador solo abarca el mundo físico. No hay, por tanto, una identificación completa entre el Uno y la luz primordial, y todas las relaciones que hemos explorado tienen que acotarse de ese modo, teniendo presente que las correspondencias y similitudes entre el Uno y la luz primordial solamente son aceptables en la medida que la luz es concebida como génesis del universo físico, y no como principio absoluto de los seres. La obra cosmológica de Grosseteste explica el origen del cosmos, de los seres sensibles, pero no hay referencia a la generación de seres no corporales -las inteligencias (los ángeles), por ejemplo, u otros seres incorpóreos-. El sistema desarrollado por Plotino es más ambicioso, más amplio, un sistema en el que el mundo corpóreo ocupa un lugar escalones abajo del principio absoluto en la cadena de generación, teniendo por encima a otros seres de índole superior. Y para ser estrictos, las ideas de Plotino comprenden, no solo la totalidad de los seres, sino que alcanzan el nivel supra ontológico propio del Uno. Todo lo que hemos dicho acerca de la luz primordial en relación con el Uno debe restringirse al terreno de lo corpóreo. Que la luz primordial es "principio", quiere decir que es "principio de los cuerpos"; que es "causa", "causa de los cuerpos"; que 
es "simple", quiere decir que es simple en el mundo sensible, que carece de dimensiones -porque, como vimos, en el marco conceptual podía verse como el compuesto de materia y forma primeras-, etcétera. En el Uno, en cambio, todos los adjetivos o predicados tienen un significado absoluto: principio absoluto, causa absoluta, absolutamente simple -no acepta ningún tipo de composición-.

En vista de la importante limitación de la correspondencia entre el Uno y la luz primordial, podría pensarse erróneamente que el Uno plotiniano se asemejaría, más bien, no a la luz primera, sino a su creador, a Dios. Pero ciertamente esta comparación no es acertada. La metafísica del Uno no se adapta a una postura creacionista. En el sistema de Plotino está ausente la idea de un principio todopoderoso que deliberadamente decide crear el universo físico. El Uno es el principio de las cosas, es verdad, es la causa de todos los seres, pero produce espontáneamente, mientras permanece en sí mismo; no tiene voluntad, nada desea, nada puede desear. La generación de la multiplicidad no es consecuencia de un acto de voluntad.

Recibido: 09/07/2016

Aceptado: 12/02/2017

\section{Bibliografia}

Crombie, A.C, Robert Grosseteste and the Origins of Experimental Science, Oxford: The Clarendon Press, 1953.

Eastwood, B., "Medieval Empiricism: the Case of Grosseteste's Optics", en: Speculum: A Journal of Mediaeval Studies, v. XLII, 2 (1968), pp. 306-321.

Eastwood, B., “Grosseteste's 'Quantitative' Law of Refraction: A Chapter in the History of Non-Experimental Science”, en: Journal for the history of ideas, v. XXIIX, 3(1967), pp. 403-414. https://doi.org/10.2307/2708626

Eastwood, S., "Metaphysical Derivation of a Law of Refraction: Damianos and Grosseteste", en: Archive for History of Exact Sciences, v. VI, 3 (1970), pp. 224-236. https:// doi.org/10.1007/BF00327236

Grant, E., A Source Book in Medieval Science, Cambridge (Mass): Harvard University Press, 1974.

Grosseteste, R, Óptica, Lértora, C. (trad.), Buenos Aires: Ediciones el Rey, 1985.

Grosseteste, R., Astronomía, Lértora, C. (trad.), Buenos Aires: Ediciones el Rey, 1988.

Grosseteste, R., Física, Lértora, C. (trad.), Buenos Aires: Ediciones el Rey, 1989.

Grosseteste, R., On Six Days of Creation, Martin, C.F.J. (trad.), Oxford: Oxford University Press, 1996, pp. 7-115.

Grosseteste, R., On light, Riedl, C. (trad.), Milwaukee: Marchette University Press, 2008. 
Igal, J., "Introducción general", en: Vida de Plotino Enéadas I-II, Igal, J. (trad), Madrid: Editorial Gredos, 1992.

Lindberg, D., "On the Applicability of Mathematics to Nature: Roger Bacon and his Predecessors", en: The British Journal for the History of Science, v. XV, 1 (1982), pp. 3-25. https://doi.org/10.1017/S0007087400018914

Lindberg, D., Los inicios de la ciencia occidental, Beltrán, A. (trad.), Barcelona: Ediciones Paidós Ibérica, 2002.

McEvoy, J., Robert Grosseteste, Oxford: Oxford University Press, 2000.

Oliver, S., "Robert Grosseteste on Light, Truth and Experimentum", en: Vivarum, v. XVII, 2 (2004), pp. 151-180. https://doi.org/10.1163/1568534043084739

Plotino, Enéadas III-IV, Igal, J. (trad.), Madrid: Gredos, 1992.

Plotino, Enéadas V-VI, Igal, J. (trad.), Madrid: Gredos, 1992.

Plotino y Porfirio, Vida de Plotino Eneadas I-II, Igal, J. (trad.), Madrid: Gredos, 1992.

Raizman-Kedar, Y., "Plotinus's Conception of Unity and Multiplicity as the Root to the Medieval Distinction Between Lux and Lumen", en: Studies in History and Philosophy of Science, v. XXXVII, 2006, pp. 379-397. https://doi.org/10.1016/j. shpsa.2006.06.006

Riedl, C., "Introduction", en: Grosseteste, R., On light, Milwaukee: Marchette University Press, 1978.

Santa Cruz, I. y M. Crespo, Plotino: de la filosofia a la mística. Enéadas: Textos esenciales, Buenos Aires: Colihue, 2007, pp. VII-LXXXVIII.

Turbayne, C., "Grosseteste and the Ancient Optical Principle", en: Isis, v. L, 4 (1959), pp. 467-472. https://doi.org/10.1086/348802 